\title{
NOTE \\ Internal Medicine \\ Multiple acquired portosystemic shunts secondary to primary hypoplasia of the portal vein in a cat
}

\author{
Satoko SUGIMOTO'1), Shingo MAEDA ${ }^{2) *}$, Masaya TSUBOI ${ }^{3)}$, Kohei SAEKI ${ }^{4)}$, \\ James K. (HAMBERS ${ }^{3)}$, Tomohiro YONEZAWA ${ }^{2)}$, Kenjiro FUKUSHIMA ${ }^{1)}$, \\ Reina FUJIWARA ${ }^{4)}$, Kazuyuki UCHIDA ${ }^{3)}$, Hajime TSUJIMOTO'1), \\ Naoaki MATSUKI ${ }^{2)}$ and Koichi OHNO ${ }^{1)}$ \\ ${ }^{1)}$ Department of Veterinary Internal Medicine, Graduate School of Agricultural and Life Sciences, \\ The University of Tokyo, 1-1-1 Yayoi, Bunkyo-ku, Tokyo 113-8657, Japan \\ ${ }^{2)}$ Department of Veterinary Clinical Pathobiology, Graduate School of Agricultural and Life Sciences, \\ The University of Tokyo, 1-1-1 Yayoi, Bunkyo-ku, Tokyo 113-8657, Japan \\ 3) Department of Veterinary Pathology, Graduate School of Agricultural and Life Sciences, \\ The University of Tokyo, 1-1-1 Yayoi, Bunkyo-ku, Tokyo 113-8657, Japan \\ ${ }^{4)}$ Department of Veterinary Surgery, Graduate School of Agricultural and Life Sciences, The University of Tokyo, \\ 1-1-1 Yayoi, Bunkyo-ku, Tokyo 113-8657, Japan
}

\section{J. Vet. Med. Sci.}

80(6): 874-877, 2018

doi: 10.1292/jvms.17-0648

Received: 3 December 2017 Accepted: 25 March 2018

Published online in J-STAGE: 9 April 2018
ABSTRACT. A 6-year 5-month-old spayed female Scottish Fold cat presented with a one-month history of gait abnormalities, increased salivation, and decreased activity. A blood test showed hyperammonemia and increased serum bile acids. Imaging tests revealed multiple shunt vessels indicating acquired portosystemic shunt. Histopathologic analysis of liver biopsy showed features consistent with liver hypoperfusion, such as a barely recognizable portal vein, increased numbers of small arterioles, and diffuse vacuolar degeneration of hepatocytes. These findings supported the diagnosis of primary hypoplasia of the portal vein/microvascular dysplasia, (PHPV/MVD). To our knowledge, this is the first case of feline PHPV/MVD that developed multiple acquired portosystemic shunts and presented with hepatic encephalopathy.

KEY WORDS: acquired portosystemic shunt, feline, hepatic encephalopathy, microvascular dysplasia, portal hypertension

Primary hypoplasia of the portal vein (PHPV) is a congenital disorder which occurs in dogs but very seldom in cats [5]. Histologically, there is a decreased portal vein diameter or absence of the portal vein and an increased number of arteriolar profiles in the portal tracts. The term, microvascular dysplasia (MVD), was previously used to identify this congenital condition. Histological features of PHPV/MVD can be seen in some other diseases causing portal vein hypoperfusion such as congenital portosystemic shunt (cPSS), intrahepatic arteriovenous (AV) fistula, and portal vein obstruction [5].

Clinical signs of canine PHPV/MVD are similar to those of cPSS, but the severity is often mild [1]. Most of them are likely to have good prognosis [4], although some dogs suffer from portal hypertension and develop multiple acquired portosystemic shunts (aPSS) [15]. Portal hypertension is the result of increased resistance to portal blood flow. The clinical consequences of portal hypertension include the development of multiple aPSS, ascites, hepatic encephalopathy, or some combination of these [3].

Unlike dogs, PHPV/MVD is rare in cats [5]. Although a few feline PHPV/MVD cases have been reported, there is no report of multiple aPSS associated with PHPV/MVD in cats. Here, we report the first feline case of PHPV/MVD which developed multiple aPSS and presented with hepatic encephalopathy.

A 6-year 5-month-old spayed female Scottish Fold cat was referred to the Veterinary Medical Center of the University of Tokyo with a one-month history of gait abnormalities, increased salivation, decreased activity, and decreased menace responses. Before referral, the cat had undergone ophthalmic examination, but no abnormalities were found. The cat was treated with ampicillin and prednisolone, but the symptoms did not improve, and eventually they progressed. The cat was current on routine vaccinations and had been housed indoors.

On physical examination, the cat was thin (BCS, 2/5) and small (BW $2.36 \mathrm{~kg}$ ) compared to normal. In the hospital, the cat staggered and easily fell down. The level of consciousness was good and no seizure was observed. Upon neurological examination,

*Correspondence to: Maeda, S.: amaeda@mail.ecc.u-tokyo.ac.jp

O2018 The Japanese Society of Veterinary Science

This is an open-access article distributed under the terms of the Creative Commons Attribution Non-Commercial No Derivatives (by-nc-nd) License. (CC-BY-NC-ND 4.0: https://creativecommons.org/licenses/by-nc-nd/4.0/) 

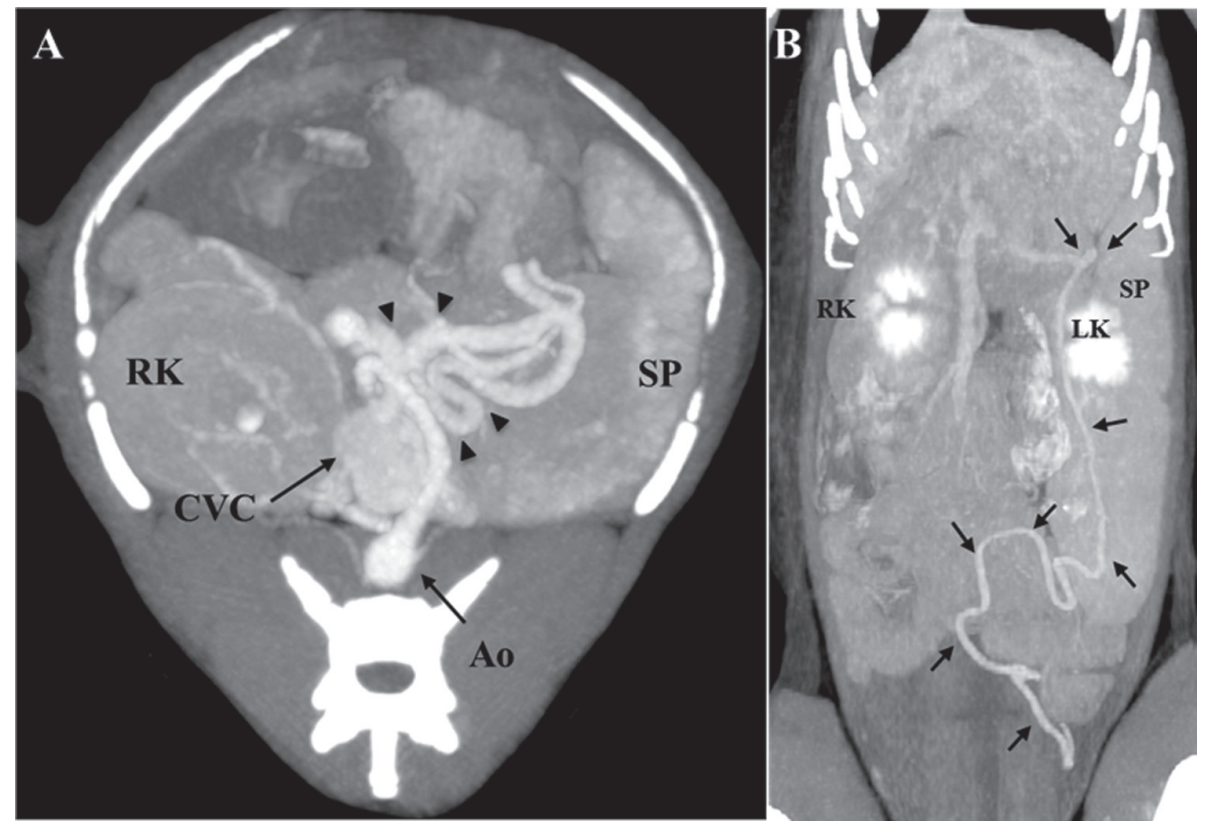

Fig. 1. Multiphase computed tomography angiography images. (A) Maximum intensity projection transvers view of the portal venous phase. Note the tortuous vessels (arrowheads). Ao, aorta; CVC, caudal vena cava; RK, right kidney; SP, spleen. (B) Maximum intensity projection coronal view of the equilibrium phase. The splenic vein (arrows) toward the caudal side and connect with the small vein around the urinary bladder.

the menace responses and the withdrawal reflex of the hind limbs were absent bilaterally, and the tactile placing response of the hind limb was decreased.

Complete blood count identified a mildly decreased hematocrit (29.2\%). Abnormalities found on serum biochemical analyses were ALT $102 \mathrm{U} / l$ (reference value, 22 to $84 \mathrm{U} / l), \mathrm{BUN} 11.9 \mathrm{mg} / \mathrm{d} l(17.6$ to $32.8 \mathrm{mg} / \mathrm{d} l), \mathrm{CRE} 0.7 \mathrm{mg} / \mathrm{d} l(0.8$ to $1.8 \mathrm{mg} / \mathrm{d} l), \mathrm{NH} / 3$ $325 \mu \mathrm{g} / \mathrm{d} l(23$ to $78 \mu \mathrm{g} / \mathrm{d} l)$, IP $2.0 \mathrm{mg} / \mathrm{d} l(2.6$ to $6.0 \mathrm{mg} / \mathrm{d} l), \mathrm{K} 2.9 \mathrm{mEq} / l(3.4$ to $4.6 \mathrm{mEq} / l)$. Fasting and postprandial serum bile acids were increased ( 115.1 and $58.6 \mu \mathrm{mol} / l$, respectively; reference value $<10.0 \mu \mathrm{mol} / l)$. Total protein, albumin, glucose, alkaline phosphatase, total bilirubin, calcium, sodium, chloride and thyroxine (T4) were within the reference ranges. The cat had tested negative for feline leukemia virus (FeLV) and feline immunodeficiency virus (FIV). Urinalysis showed no abnormalities. Abdominal ultrasonography identified multiple small, tortuous, aberrant vessels in cranial to the left kidney. No renal calculus or cystolith was observed. Other abdominal organs, including gall bladder, spleen, kidneys, adrenal glands, pancreas and intestines, were normal.

Helical computed tomography (CT) of the whole body was performed acquiring contiguous, 1-mm thick transverse images using an 80-slice multi-detector device with a pitch of 0.81 (Aquilion PRIME, Toshiba Medical Systems Co., Ltd., Tokyo, Japan). A single injection of iodinated contrast agent (Iohexol; Omnipaque, Daiichi Sankyo Co., Ltd., Tokyo, Japan) was administered intravenously (600 mgI/kg) and angiographic scans were acquired immediately, and 20, 40 and 120 sec post-injection. The CT examination confirmed multiple vascular abnormalities, including a tortuous vessel connecting the splenic vein with the left renal vein (Fig. 1A), multiple tiny and tortuous vessels close to the left kidney (Supplemental Movie 1), and connecting the splenic vein with the small vein around the urinary bladder (Fig. 1B and Supplemental Movie 2). Portal vein was dilated at the porta hepatis, and subsequent intrahepatic portal vein branches were thin and tortuous (Supplemental Movie 3). The liver parenchyma showed patchy enhancement.

Since the owner did not want further investigations, supportive therapy with lactulose $(1 \mathrm{~g} / \mathrm{head}$; Monilac, Chugai Pharmaceutical Co., Ltd., Tokyo, Japan) orally twice a day, metronidazole (13 mg/kg; Flagyl, Shionogi \& Co., Ltd., Osaka, Japan) orally twice a day, and a commercial therapeutic diet for hepatic health (Prescription Diet 1/d Cat, Hill's-Colgate Japan Ltd., Tokyo, Japan) were started.

Six months after the initial presentation, the cat returned for an exploratory laparotomy because of recurrent hyperammonemia and symptoms, including salivation and wandering. Coagulation testing was performed on citrated plasma. Prothrombin time was $11.0 \mathrm{sec}$ (reference value, 8 to $11 \mathrm{sec}$ ), activated partial thromboplastin time was $53.4 \mathrm{sec}(21$ to $45 \mathrm{sec})$ and fibrinogen was $51 \mathrm{mg} /$ $\mathrm{d} l(90$ to $250 \mathrm{mg} / \mathrm{d} l)$. On gross examination, multiple small, tortuous blood vessels were noted in cranial to the left kidney. The liver was mottled in color, and the edge of the liver was rounded. No ascites was observed. Two liver biopsy specimens were taken from left and right medial lobe, and they submitted for histopathological analysis.

Histopathologic evaluation revealed scarcely recognizable portal vein (Fig. 2A), increased numbers of small arterioles aberrantly located within the portal triad, mild fibrosis, and mild lymphocyte infiltration (Fig. 2B). Diffuse vacuolar degeneration of hepatocytes and mild sinusoidal congestion were present throughout the hepatic parenchyma. Taken together, this case was diagnosed as PHPV/MVD with multiple aPSS and hepatic encephalopathy. 

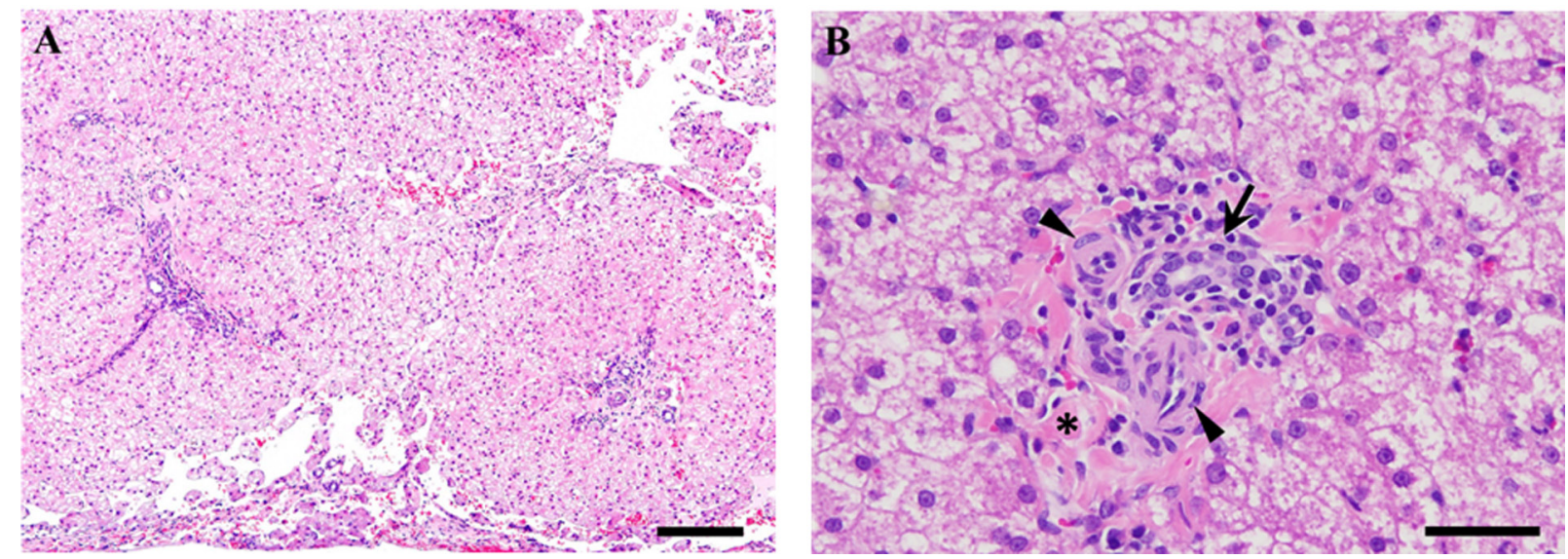

Fig. 2. Histopathological findings of liver biopsy (hematoxylin and eosin). (A) Scarcely recognizable portal vein and diffuse vacuolar degeneration of hepatocytes were present throughout the hepatic parenchyma. Bar, $200 \mu \mathrm{m}$. (B) A representative image of portal triad. There is absence of the portal vein and an increased number of arteriolar profiles (arrowheads), mild fibrosis (asterisk). The arrow indicates bile duct. Bar, $100 \mu \mathrm{m}$.

The dosage of lactulose was increased to $2 \mathrm{~g}$ /head twice a day, and metronidazole and commercial therapeutic diet were continued for symptomatic therapy of hepatic encephalopathy. At the time of writing this article, 477 days since initial presentation, the cat is still alive. Her hepatic encephalopathy is well controlled and her quality of life is good.

To our knowledge, there are only two reports of feline PHPV/MVD without macroscopic PSS [6, 16]. The first case was a 9-month-old Birman that had episodes of ptyalism, apathy, and abnormal behavior (circling) with increased pre- and post-prandial bile acids and ammonia. A macroscopic shunt was not found on surgical abdominal exploration, and liver biopsy confirmed hepatic portovenous hypoplasia; therefore, PHPV was suspected [16]. The second case was a domestic shorthair cat that presented with a clinically suspected PSS and was diagnosed with MVD without a macrovascular PSS [6]. However, there were no detailed descriptions and prognosis reports of the cats with PHPV/MVD in these reports.

PHPV/MVD is commonly associated with cPSS in dogs [7]. In contrast, there are few reports of PHPV/MVD accompanied with cPSS in cats $[6,7]$. At our institution, 30 cats were histologically diagnosed with PHPV/MVD by liver biopsy, from April 2008 to June 2017; in 26 cats, it was associated with cPSS, in two, it was associated with AV fistula, in one, there was no definitive diagnosis, and only one case of PHPV/MVD without macroscopic congenital anomalies (the present case) was observed (unpublished data). This result suggests that most PHPV/MVD cases are associated with cPSS in cats as well as in dogs.

Dogs with PHPV/MVD frequently have less severe clinical signs and a better long-term prognosis than do those with a PSS that are managed medically [4]. However, it is known that PHPV/MVD rarely forms multiple aPSS from portal hypertension and exhibits severe symptoms, such as hepatic encephalopathy. In a report of $42 \mathrm{dogs}$ diagnosed with portal hypertension caused by PHPV/MVD, most of the dogs died naturally or were euthanized owing to the progression of the disease within the first few weeks [15]. In cats, it is unknown whether the formation of multiple aPSS indicates poor prognosis. In the present case, although formation of multiple aPSS was observed, the cat had good quality of life for 477 days, using supportive therapy for hepatic encephalopathy.

In the present case, the symptoms of hepatic encephalopathy occurred at middle age. The possible explanations are as follows: (1) congenital PHPV had been asymptomatic at young age but then symptomatic multiple aPSS with hepatic encephalopathy was developed at middle age; or (2) the owner was not aware of the symptoms although multiple aPSS with hepatic encephalopathy was developed.

One limitation is that portal vein pressure was not measured in this case. However, multiple portosystemic collateral vessels were observed in the present case, which strongly indicates portal hypertension. Multiple aPSS develop as a result of prehepatic or intrahepatic portal hypertension [3]. Contrary to cPSS, ligation of the multiple shunt vessels in aPSS is contraindicated. It is necessary to treat the underlying diseases. According to the previous 11 case reports of feline multiple aPSS, the cause were describes as follows: four cats had developed it after ligation of cPSS [8, 16, 17], two had portal vein thrombus [13, 14], two had congenital hepatic fibrosis [18], one had hepatic AV fistula [10], one had bile duct adenocarcinoma [9], one had chronic cholangitis [9], and four had no mention of the diagnosis [2, 11, 12]. Since liver cirrhosis is rare in cats, it is necessary to recognize that the underlying diseases in cats with multiple aPSS are different from those in dogs.

To our knowledge, the present case is the first feline case of multiple aPSS secondary to PHPV/MVD, suggesting that PHPV/ MVD should be considered in the differential diagnosis of aPSS. Further epidemiological studies are required to characterize this rare disorder.

ACKNOWLEDGMENT. The authors thank Dr. Hiroyuki Abe (Hiro Animal Hospital) for introducing the case described in this report. 


\section{REFERENCES}

1. Allen, L., Stobie, D., Mauldin, G. N. and Baer, K. E. 1999. Clinicopathologic features of dogs with hepatic microvascular dysplasia with and without portosystemic shunts: 42 cases (1991-1996). J. Am. Vet. Med. Assoc. 214: 218-220. [Medline]

2. Bertolini, G. 2010. Acquired portal collateral circulation in the dog and cat. Vet. Radiol. Ultrasound 51: 25-33. [Medline] [CrossRef]

3. Buob, S., Johnston, A. N. and Webster, C. R. 2011. Portal hypertension: pathophysiology, diagnosis, and treatment. J. Vet. Intern. Med. 25: 169-186. [Medline] [CrossRef]

4. Christiansen, J. S., Hottinger, H. A., Allen, L., Phillips, L. and Aronson, L. R. 2000. Hepatic microvascular dysplasia in dogs: a retrospective study of 24 cases (1987-1995). J. Am. Anim. Hosp. Assoc. 36: 385-389. [Medline] [CrossRef]

5. Cullen, J. M., Van den Ingh, T. S. G. A. M., Bunch, S. E., Rothuizen, J., Washabau, R. J. and Desmet, V. J. 2006. Morphological classification of circulatory disorders of the canine and feline liver. pp. 41-59. In: WSAVA Standards for Clinical and Histological Diagnosis of Canine and Feline Liver Disease, 1st ed. (Rothuizen, J., Bunch, S. E., Charles, J. A., Cullen, J. M., Desmet, V. J., Szatmari, V., Twedt, D. C., Van den ingh, T. S. G. A. M., Winkle, T. V. and Washabau, R. J. eds.), Elsevier, Philadelphia.

6. d'Anjou, M. A., Penninck, D., Cornejo, L. and Pibarot, P. 2004. Ultrasonographic diagnosis of portosystemic shunting in dogs and cats. Vet. Radiol. Ultrasound 45: 424-437. [Medline] [CrossRef]

7. Hirose, N., Uchida, K., Kanemoto, H., Ohno, K., Chambers, J. K. and Nakayama, H. 2014. A retrospective histopathological survey on canine and feline liver diseases at the University of Tokyo between 2006 and 2012. J. Vet. Med. Sci. 76: 1015-1020. [Medline] [CrossRef]

8. Hunt, G. B., Kummeling, A., Tisdall, P. L., Marchevsky, A. M., Liptak, J. M., Youmans, K. R., Goldsmid, S. E. and Beck, J. A. 2004. Outcomes of cellophane banding for congenital portosystemic shunts in 106 dogs and 5 cats. Vet. Surg. 33: 25-31. [Medline] [CrossRef]

9. Langdon, P., Cohn, L. A., Kreeger, J. M. and Priddy, N. H. 2002. Acquired portosystemic shunting in two cats. J. Am. Anim. Hosp. Assoc. 38: 21-27. [Medline] [CrossRef]

10. McConnell, J. F., Sparkes, A. H., Ladlow, J., Doust, R. and Davies, S. 2006. Ultrasonographic diagnosis of unusual portal vascular abnormalities in two cats. J. Small Anim. Pract. 47: 338-343. [Medline] [CrossRef]

11. Morandi, F., Sura, P. A., Sharp, D. and Daniel, G. B. 2010. Characterization of multiple acquired portosystemic shunts using transplenic portal scintigraphy. Vet. Radiol. Ultrasound 51: 466-471. [Medline] [CrossRef]

12. Palerme, J. S., Brown, J. C., Marks, S. L. and Birkenheuer, A. J. 2013. Splenosystemic shunts in cats: a retrospective of 33 cases (2004-2011). J. Vet. Intern. Med. 27: 1347-1353. [Medline] [CrossRef]

13. Rogers, C. L., O’Toole, T. E., Keating, J. H., Penninck, D. G. and Webster, C. R. 2008. Portal vein thrombosis in cats: 6 cases (2001-2006). J. Vet. Intern. Med. 22: 282-287. [Medline] [CrossRef]

14. Specchi, S., Pey, P., Ledda, G., Lustgarten, M., Thrall, D. and Bertolini, G. 2015. Computed tomographic and ultrasonographic characteristics of cavernous transformation of the obstructed portal vein in small animals. Vet. Radiol. Ultrasound 56: 511-519. [Medline] [CrossRef]

15. Van den Ingh, T. S., Rothuizen, J. and Meyer, H. P. 1995. Portal hypertension associated with primary hypoplasia of the hepatic portal vein in dogs. Vet. Rec. 137: 424-427. [Medline] [CrossRef]

16. Vandermeulen, E., Combes, A., de Rooster, H., Polis, I., de Spiegeleer, B., Saunders, J. and Peremans, K. 2013. Transsplenic portal scintigraphy using $99 \mathrm{mTc}$-pertechnetate for the diagnosis of portosystemic shunts in cats: a retrospective review of 12 patients. J. Feline Med. Surg. 15: 1123-1131. [Medline] [CrossRef]

17. Vogt, J. C., Krahwinkel, D. J. Jr., Bright, R. M., Daniel, G. B., Toal, R. L. and Rohrbach, B. 1996. Gradual occlusion of extrahepatic portosystemic shunts in dogs and cats using the ameroid constrictor. Vet. Surg. 25: 495-502. [Medline] [CrossRef]

18. Zandvliet, M. M., Szatmári, V., van den Ingh, T. and Rothuizen, J. 2005. Acquired portosystemic shunting in 2 cats secondary to congenital hepatic fibrosis. J. Vet. Intern. Med. 19: 765-767. [Medline] [CrossRef] 